\title{
Evaluation of allelopathic potential of safflower genotypes (Carthamus tinctorius L.)
}

\author{
Marzieh Motamedi, Hassan Karimmojeni*, Fatemeh Ghorbani Sini
}

Department of Agronomy and Plant Breeding, College of Agriculture, Isfahan University of Technology, Isfahan, 84156-8311, Iran

Received: April 10, 2016

Accepted: October 13, 2016

\begin{abstract}
Forty safflower genotypes were grown under normal irrigation and drought stress. In the first experiment, the allelopathic potential of shoot residues was evaluated using the sandwich method. Each genotype residue $(0.4 \mathrm{~g})$ was placed in a sterile Petri dish and two layers of agar were poured on that. Radish seeds were placed on agar medium. The radish seeds were cultivated without safflower residues as the controls. The length of the radicle, hypocotyl, and fresh biomass weight and seed germination percentages were measured. A pot experiment was also done on two genotypes with the highest and two with the lowest allelopathic activity selected after screening genotypes in the first experiment. Before entering the reproductive phase, irrigation treatments (normal irrigation and drought stress) were applied. Shoots were harvested, dried, milled and mixed with the topsoil of new pots and then radish seeds were sown. The pots with safflower genotypes were used to evaluate the effect of root residue allelopathy. The shoot length, fresh biomass weight and germination percentage were measured. Different safflower genotypes showed varied allelopathic potential. The results of the first experiment showed that Egypt and Iran-Khorasan genotypes caused maximum inhibitory responses and Australia and Iran-Kerman genotypes resulted in minimum inhibitory responses on radish seedling growth. Fresh biomass weight had the most sensitivity to safflower residues. The results of the pot experiment were consistent with the results of in vitro experiments. Residues produced under drought stress had more inhibitory effects on the measured traits. Safflower root residue may have a higher level of allelochemicals or different allelochemicals than shoot residue.
\end{abstract}

Key words: allelopathy, drought stress, sandwich method, safflower, radish

\section{Introduction}

Safflower (Carthamus tinctorius L.) is an oilseed crop, which is grown all over the world for its high-quality oil and red and orange pigments extracted from its flowers. In recent years, safflower cultivation has increased as it is well-adapted to varied growth conditions, in particular to arid and semi-arid climates (Yousefi Davood et al. 2013).

Since weeds have been identified as an important factor in crop yield and crop quality reduction, weed control is crucial. Cultural, mechanical, chemical and biological methods are the major factors in weed management. Among them, the use of herbicides is the principal method of managing weeds within a vast range of cropping systems (Powles et al. 1996). Mechanical control is expensive and chemical control causes environmental issues and resistant weed biotypes emerge as a result of extensive and repetitive application of a particular type of herbicide. Biological control using allelopathic properties of plants is an alternative way of improving weed management. Recently worldwide demand for cheaper and more environmentally-friendly weed management technologies have inspired a number of researchers to study the interaction between crops and weeds (Om et al. 2002; Albuquerque et al. 2011; Itani et al. 2013).
Allelopathy refers to both positive and negative biochemical interactions between all types of plants (Molisch 1937; Pedrol et al. 2006; Kabir et al. 2010). These biochemical interactions are related to inhibitory and stimulatory substances that are released directly from living plants into the environment by different mechanisms such as root exudation, leaching, volatilisation, as well as through the decomposition of plant residues (Rice 1984). Whittaker and Feeny (1971) named these phytotoxic substances "allelochemicals". Environmental conditions, e.g. temperature, rainfall and moisture stress, light and nutrient status affect the concentration of allelochemicals in the donor plants. In other words, the allelopathic potential of plants is heavily affected by biotic and abiotic stresses. Drought, irradiation, competitors, nutrient limitation, temperature, disease and pest damage influence the release of allelochemicals from allelopathic plants. Plants grown in dry soils show more allelopathic activity than those grown in well-watered soils (Einhellig 1995). Furthermore, different types of allelopathic interactions occur in plants grown in dry soils compared to plants grown in well-watered soils (Einhellig 1995; Vidal and Bauman 1997; Albuquerque et al. 2011).

It is difficult to separate resource competition from allelopathy under field conditions. Thus, different labora- 
tory screening techniques have been applied to measure allelopathy without the interference of resource competition. The sandwich method (Fujii et al. 2003), agar medium selection (Fujii 1992; Wu et al. 1999), the plant box method (Fujii 1994; Nishihara et al. 2005) and relay seedling (Navarez and Olofsdotter 1996) have been tested for bioassays. The sandwich method is an effective tool to screen for allelopathic properties under laboratory conditions. This method is less time-consuming and can be applied to screen a great number of samples.

Allelopathic potential of safflower has been reported in several studies. Miri (2011) indicated that safflower significantly reduced the germination and root and shoot growth of wild barley (Hordeum spontaneum L.) and has great potential for management of this weed in wheat (Triticum aestivum L.) production. Farhoudi and Lee (2012) showed that safflower extracts inhibited the induction of $\alpha$-amylase in wild mustard (Sinapis arvensis L.) seeds. Modhej et al. (2013) found that wild mustard seedling growth and seed germination were negatively affected by safflower allelopathic extract. Furthermore, Bonamigo et al. (2013) demonstrated that seedling emergence and early growth stages of canola (Brassica napus L.) were negatively affected by safflower aqueous extracts.

Little is known about safflower allelopathic potential. Therefore, the overall objective of this study was to evaluate the allelopathic potential of 40 genotypes of safflower (Carthamus tinctorius L.) shoot residues under both normal and drought conditions using the sandwich method and to screen out highly allelopathic genotypes. A pot experiment was also carried out on four selected safflower genotypes to determine the allelopathic potential of their shoot and root residues using radish as a test plant.

\section{Materials and Methods}

\section{In vitro experiment}

Plant material

Forty safflower genotypes were grown in two moisture environments including normal conditions and drought stress at the research farm of the Isfahan University of Technology located at Lavark, Najaf-Abad, Iran (40 km southwest of Isfahan, $32^{\circ} 32^{\prime} \mathrm{N}, 51^{\circ} 23^{\prime} \mathrm{E}, 1,630 \mathrm{~m}$ asl). Details of plant material including name and origin are given in Table 1.

\section{Irrigation treatments}

Plots received the same irrigation and agronomic management up to the heading stage of safflower genotypes. Irrigation treatments were applied after the heading stage. For normal conditions, irrigation was supplied when $45 \%$ of the total available water was depleted from the root zone. Drought treatments were irrigated when $85 \%$ of the total available water was depleted (Allen et al. 1998). The number of days between two irrigations (irrigation intervals) varied since the evapotranspiration changed during the growing season. Thus, the irrigation intervals were 5-9 days for normal conditions and 14-28
Table 1. List of safflower genotypes (Carthamus tinctorius) used in this study

\begin{tabular}{|c|c|c|}
\hline No. & Origin & Name \\
\hline 1 & Iraq & PI 253762 \\
\hline 2 & Iran (Kashan) & CTNIR7 \\
\hline 3 & Afghanistan & PI 426189 \\
\hline 4 & Poland & PI 311737 \\
\hline 5 & Bangladesh & PI 401470 \\
\hline 6 & Syria & PI 386174 \\
\hline 7 & Nebraska & PI 572426 \\
\hline 8 & India & PI 657787 \\
\hline 9 & Iran (Kerman) & CTNIR9 \\
\hline 10 & Greece & PI 254976 \\
\hline 11 & Italy & PI 253522 \\
\hline 12 & Rome & CART 87 \\
\hline 13 & Belgium & CART 126 \\
\hline 14 & Poland & CART 55 \\
\hline 15 & Iran (Kordestan) & CTNIR6 \\
\hline 16 & Mexico & PI 657790 \\
\hline 17 & Israel & PI 306684 \\
\hline 18 & Thailand & PI 387821 \\
\hline 19 & Pakistan & CART 124 \\
\hline 20 & Mexico & PI 657789 \\
\hline 21 & Hungary & PI 253541 \\
\hline 22 & Cyprus & PI 532619 \\
\hline 23 & DEU & CART 132 \\
\hline 24 & Syria & PI 386173 \\
\hline 25 & Paraguay & CART 131 \\
\hline 26 & Japan & CART 79 \\
\hline 27 & Iran (Shiraz) & CTNIR8 \\
\hline 28 & Uzbek & PI 369843 \\
\hline 29 & Egypt & PI 657800 \\
\hline 30 & Iran (Darab) & Darab2 \\
\hline 31 & Iran (Hamedan) & Hamedan21 \\
\hline 32 & Iran (Marand) & Marand \\
\hline 33 & Iran (Khorasan) & Khorasan330 \\
\hline 34 & Poland & PI 253544 \\
\hline 35 & Australia & PI 262424 \\
\hline 36 & France & PI 198843 \\
\hline 37 & Italy & PI 253521 \\
\hline 38 & Iran & CTNIR1 \\
\hline 39 & Jordan & PI 657820 \\
\hline 40 & Iran & CTNIR4 \\
\hline
\end{tabular}

days for stress conditions. Three soil samples were taken per plot at depths of 0-20, 20-40, and 40-60 cm for both normal and drought stress conditions every second day between two irrigations and just a day before irrigation to measure the gravimetric soil water content. The irrigation depth was calculated according to the following equation:

$$
I=\left[\frac{(F C-\Theta)}{100}\right] D \times B
$$

where: $I$ - irrigation depth $(\mathrm{cm}) ; F C$ - soil gravimetric moisture percent at field capacity; $\theta$ - soil gravimetric moisture percentage at irrigation time; $D$ - the root-zone depth; $B$ - the soil bulk density at root zone $\left(1.4 \mathrm{~g} \cdot \mathrm{cm}^{-3}\right)$. 
Water was supplied using a basin irrigation system. In this type of surface irrigation, water is applied to a completely level area surrounded by dikes. Water was delivered from a pumping station by a polyethylene pipe. The water volume was determined using a volumetric counter.

The gross depth of irrigation was also calculated based on the following formula:

$$
I g=\frac{I}{E a} \times 100
$$

where: $I g$ - the gross depth of irrigation $(\mathrm{cm}) ; I$ - irrigation depth (cm); $E a$ - the irrigation efficiency (\%) assumed as $75 \%$ during the growing season.

The plant shoot residues, except the inflorescence part of each genotype grown under both normal and drought stress conditions, were collected from the field and stored separately in paper bags. These materials were air dried at room temperature. Dried materials were kept in plastic bags at room temperature until used. In order to study the allelopathic effects of these residues, the radish seed (Raphanus sativus L.) was used as a test plant due to its sensitivity to chemical inhibitors and stimulators and its fast germination and growth. Radish seeds were surface sterilized with $3 \%$ sodium hypochlorite for $10 \mathrm{~min}$, and thoroughly rinsed with sterilized distilled water. Radish seeds were also sterilized with fungicide Rovral ${ }^{\circledR} 50 \mathrm{WP}$ (iprodione) to prevent fungal contamination. For treatment, $100 \mathrm{~g}$ of radish seeds and the fungicide were placed in a conical flask. The flask was tightly closed with a polystyrene cork and hand shaken for about $10 \mathrm{~min}$ to uniformly coat the seeds with the fungicide.

\section{Preparation of growth medium}

Based on the results of Fujii et al. (2003) agar growth medium in the sandwich method was found to be the best method for radish seedling growth. Agar $(0.5 \% \mathrm{w} / \mathrm{v})$ was also applied as the growth medium. During the experiments, the culture medium and all devices were sterilized by autoclave at $121^{\circ} \mathrm{C}$ and transferred to a tissue culture room.

\section{Growth conditions and growth measurement}

In order to perform the experiment, $0.4 \mathrm{~g}$ residue of each genotype grown under both normal and stress conditions was placed in a sterile Petri dish and subsequently two layers of agar (each $5 \mathrm{ml}$ ) were poured on the dried residues. Thirty radish seeds were placed on agar medium. The Petri dishes were sealed with parafilm and wrapped in aluminum foil in order to create dark conditions. The radish seeds were also cultivated without safflower residues as a control. These Petri dishes were kept in a germinator $\left[11: 13 \mathrm{~h}(\mathrm{~L}: \mathrm{D})\right.$ at $\left.13-25^{\circ} \mathrm{C}\right]$ for 3 days. After this incubation time, the length of the radicle and hypocotyl and fresh biomass weight were measured and the seed germination percentages were recorded.

The factorial experiment with two factors including safflower genotypes and irrigation treatments was conducted based on completely randomized design.

\section{Pot experiment}

In order to determine the allelopathic effect of safflower residues produced under normal irrigation and drought stress, a pot experiment was carried out on four genotypes selected after screening 40 safflower genotypes grown under normal irrigation in the first experiment. Two genotypes with the highest inhibitory effects and two genotypes with the lowest inhibitory effects were used in this experiment. Before cultivation, the amount of sand that was used as a culture medium was dried for $48 \mathrm{~h}$ in the shade. Then, a plastic pot, was filled with $1 \mathrm{~kg}$ sand and weighed $(1.2 \mathrm{~kg})$. The sand was watered, until it was saturated. The pot was then covered with a plastic cover and was weighed again after $36 \mathrm{~h}$. This weight $(1.5 \mathrm{~kg})$ was considered as field capacity (FC). The difference between the weight of dry soil and the field capacity was considered to be the amount of available water (300 g). Therefore, watering was done according to the amount of available water. At the time of planting, the seeds of four safflower genotypes were prepared and planted in pots containing sand. Watering was done every three days. Pots were kept in a growth chamber at $30^{\circ} \mathrm{C}$ for two months. After the seedling establishment and before entering the reproductive phase, irrigation treatments were applied for a month on two levels. At the first level (normal irrigation) irrigation was done every three days on half pots and at the second level (drought stress), every six days on the other half. Then, shoots were harvested and placed in the shade for $48 \mathrm{~h}$, until completely dried. The residues were milled. New pots were then filled with sand and $14 \mathrm{~g}$ of residues were mixed with five centimeters of top soil. Then, in each pot 15 radish seeds (as test plants) were sown. The pots with safflower genotypes used as a medium grew radishes in order to evaluate the allelopathic effect of root residue. Then, the pots were kept in a growth chamber at $25^{\circ} \mathrm{C}$ for 2 weeks. On the fifth day after planting, radish seedlings were thinned. In the second week after planting, seedlings were harvested and shoot length, fresh biomass weight, and germination percentage were measured.

The factorial experiment with three factors used a completely randomized design. The first factor was the type of safflower genotype with four levels. The second factor was irrigation with two levels, normal irrigation and drought stress. The third factor was the type of plant part used as a residue with two levels of root and shoot residues.

\section{Results}

\section{In vitro experiment}

The type of safflower genotype and irrigation level had significant effects on all studied germination traits of radish at $1 \%$ level. The interaction effect had no significant impact on measured traits, but its impact on the germination percentage was significant at $1 \%$ level (Table 2). The findings revealed that drought stress led to increased allelopathic potential of safflower residues and inhibition on radish radicle and root length, fresh biomass weight 
Table 2. Variance analysis of radish germination traits affected by studied safflower genotypes (in vitro)

\begin{tabular}{lccccc}
\hline \multicolumn{1}{c}{ Source of variation } & $\begin{array}{c}\text { Degree of } \\
\text { freedom }\end{array}$ & Radicle length & Hypocotyl length & $\begin{array}{c}\text { Fresh biomass } \\
\text { weight }\end{array}$ & $\begin{array}{c}\text { Germination } \\
\text { percentage }\end{array}$ \\
\hline Genotypes & 39 & $6.3895^{* *}$ & $3.7234^{* *}$ & $0.00018471^{* *}$ & $0.3703^{* *}$ \\
Irrigation level & 1 & $0.0260^{* *}$ & $0.0667^{* *}$ & $0.00000346^{* *}$ & $0.00000167^{* *}$ \\
Genotypes $\times$ irrigation level & 39 & $0.0115 \mathrm{~ns}$ & $0.0320 \mathrm{~ns}$ & $0.00000203 \mathrm{~ns}$ & $0.0750^{* *}$ \\
Experimental error & 160 & 0.2141 & 0.4576 & 0.00002944 & 0.0551 \\
\hline CV\% & & 7.93 & 9.51 & 11.07 & 10.12 \\
\hline
\end{tabular}

**significant at the $1 \%$ probability level; ns - not significant

Table 3. Mean comparison for germination traits of radish affected by allelopathic potential of safflower genotypes (in vitro)

\begin{tabular}{|c|c|c|c|c|c|c|c|c|}
\hline \multirow{2}{*}{ No. } & \multicolumn{2}{|c|}{$\begin{array}{l}\text { Radicle length } \\
{[\mathrm{cm}]}\end{array}$} & \multicolumn{2}{|c|}{$\begin{array}{l}\text { Hypocotyl length } \\
{[\mathrm{cm}]}\end{array}$} & \multicolumn{2}{|c|}{$\begin{array}{l}\text { Fresh biomass weight } \\
{[\mathrm{g}]}\end{array}$} & \multicolumn{2}{|c|}{ Germination percentage } \\
\hline & stress & normal & stress & normal & stress & normal & stress & normal \\
\hline 1 & 0.5635 & 0.6192 & 0.5102 & 0.5886 & 0.0039 & 0.0040 & 12.6 & 13.0 \\
\hline 2 & 0.5999 & 0.6436 & 0.5171 & 0.5655 & 0.0039 & 0.0041 & 14.6 & 15.6 \\
\hline 3 & 0.3958 & 0.2123 & 0.5736 & 0.5971 & 0.0037 & 0.0041 & 20.0 & 20.0 \\
\hline 4 & 0.4163 & 0.4292 & 0.5696 & 0.5820 & 0.0026 & 0.0038 & 19.3 & 20.6 \\
\hline 5 & 0.6749 & 0.6923 & 0.6900 & 0.7067 & 0.0047 & 0.0049 & 20.3 & 22.6 \\
\hline 6 & 0.5882 & 0.6193 & 0.6488 & 0.6787 & 0.0045 & 0.0047 & 13.6 & 20.0 \\
\hline 7 & 0.4866 & 0.4892 & 0.5772 & 0.6138 & 0.0040 & 0.0042 & 17.6 & 20.3 \\
\hline 8 & 0.4512 & 0.4646 & 0.5977 & 0.6380 & 0.0043 & 0.0044 & 19.0 & 21.3 \\
\hline 9 & 0.7638 & 0.7787 & 0.7521 & 0.7626 & 0.0050 & 0.0053 & 22.3 & 25.0 \\
\hline 10 & 0.6714 & 0.7166 & 0.7191 & 0.7575 & 0.0046 & 0.0051 & 19.3 & 24.0 \\
\hline 11 & 0.5159 & 0.5460 & 0.6187 & 0.6600 & 0.0042 & 0.0046 & 17.6 & 23.3 \\
\hline 12 & 0.4059 & 0.4183 & 0.5785 & 0.6016 & 0.0040 & 0.0042 & 18.0 & 19.6 \\
\hline 13 & 0.4183 & 0.4260 & 0.5282 & 0.5638 & 0.0037 & 0.0039 & 20.0 & 21.0 \\
\hline 14 & 0.3749 & 0.3919 & 0.5321 & 0.5414 & 0.0036 & 0.0038 & 20.3 & 21.3 \\
\hline 15 & 0.3895 & 0.4040 & 0.5312 & 0.5583 & 0.0036 & 0.0039 & 14.3 & 19.6 \\
\hline 16 & 0.5402 & 0.4531 & 0.5681 & 0.5284 & 0.0042 & 0.0037 & 19.0 & 20.0 \\
\hline 17 & 0.3636 & 0.3786 & 0.4988 & 0.5080 & 0.0035 & 0.0035 & 17.3 & 19.6 \\
\hline 18 & 0.3485 & 0.3550 & 0.5615 & 0.5533 & 0.0038 & 0.0038 & 11.0 & 17.0 \\
\hline 19 & 0.5052 & 0.5189 & 0.6071 & 0.6333 & 0.0041 & 0.0044 & 20.0 & 24.6 \\
\hline 20 & 0.5402 & 0.5526 & 0.5681 & 0.6374 & 0.0042 & 0.0044 & 14.0 & 19.0 \\
\hline 21 & 0.3970 & 0.4001 & 0.4764 & 0.5236 & 0.0034 & 0.0036 & 19.0 & 20.0 \\
\hline 22 & 0.1725 & 0.1910 & 0.2460 & 0.2712 & 0.0017 & 0.0019 & 16.6 & 19.3 \\
\hline 23 & 0.4157 & 0.4200 & 0.5562 & 0.5740 & 0.0031 & 0.0040 & 15.6 & 19.6 \\
\hline 24 & 0.4408 & 0.4662 & 0.6885 & 0.7147 & 0.0047 & 0.0049 & 18.6 & 19.6 \\
\hline 25 & 0.5130 & 0.5396 & 0.4540 & 0.4577 & 0.0030 & 0.0032 & 12.6 & 17.0 \\
\hline 26 & 0.5137 & 0.5270 & 0.5386 & 0.5270 & 0.0038 & 0.0041 & 19.3 & 23.6 \\
\hline 27 & 0.5217 & 0.5329 & 0.5964 & 0.6080 & 0.0042 & 0.0042 & 12.3 & 21.3 \\
\hline 28 & 0.4017 & 0.4188 & 0.5364 & 0.5524 & 0.0037 & 0.0038 & 15.6 & 20.0 \\
\hline 29 & 0.0248 & 0.0250 & 0.1082 & 0.2216 & 0.0010 & 0.0015 & 6.6 & 7.3 \\
\hline 30 & 0.4240 & 0.4541 & 0.5671 & 0.5910 & 0.0038 & 0.0041 & 20.3 & 21.3 \\
\hline 31 & 0.4881 & 0.5078 & 0.5612 & 0.5983 & 0.0041 & 0.0042 & 19.6 & 22.6 \\
\hline 32 & 0.2114 & 0.2234 & 0.7050 & 0.7132 & 0.0048 & 0.0050 & 15.3 & 18.3 \\
\hline 33 & 0.0078 & 0 & 0.1730 & 0.2111 & 0.0012 & 0.0032 & 2.0 & 4.0 \\
\hline 34 & 0.4165 & 0.4273 & 0.5551 & 0.5751 & 0.0039 & 0.0040 & 16.6 & 20.0 \\
\hline 35 & 0.7949 & 0.8362 & 0.7189 & 0.8276 & 0.0046 & 0.0052 & 21.3 & 25.3 \\
\hline 36 & 0.5332 & 0.5672 & 0.5343 & 0.5711 & 0.0037 & 0.0039 & 15.6 & 20.3 \\
\hline 37 & 0.3889 & 0.4318 & 0.5855 & 0.6126 & 0.0039 & 0.0043 & 18.0 & 19.3 \\
\hline 38 & 0.3616 & 0.4087 & 0.5061 & 0.5358 & 0.0034 & 0.0037 & 19.3 & 19.6 \\
\hline 39 & 0.4771 & 0.4991 & 0.5641 & 0.5862 & 0.0041 & 0.0041 & 12.3 & 19.3 \\
\hline 40 & 0.6547 & 0.6781 & 0.5220 & 0.5512 & 0.0036 & 0.0038 & 12.3 & 18.3 \\
\hline LSD 5\% & 0.0320 & 0.0610 & 0.0540 & 0.0920 & 0.00043 & 0.00071 & 3.4318 & 2.91 \\
\hline $\begin{array}{c}\text { LSD } \\
\text { interaction }\end{array}$ & \multicolumn{2}{|c|}{0.3057} & \multicolumn{2}{|c|}{0.0748} & \multicolumn{2}{|c|}{0.00031} & \multicolumn{2}{|c|}{3.1222} \\
\hline
\end{tabular}


and germination percentage in comparison with normal irrigation. Among the measured traits, fresh biomass weight had the most sensitive to safflower residues, i.e. residues which caused a decrease in biomass production (Tables 3, 5, 6).

Among the genotypes grown under normal irrigation, Australia (PI 262424) and Kerman (CTNIR9) genotypes had the minimum and Khorasan (Khorasan330) and Egypt (PI 657800) genotypes had the maximum inhibitory effects on radish radicle length, hypocotyl length, fresh biomass weight and germination percentage (Table 3 ).

Among the safflower genotypes grown under drought stress, Australia (PI 262424) and Kerman (CTNIR9) genotypes possessed the least inhibition on radish radicle length, hypocotyl length, fresh biomass weight and germination percentage. Bangladesh (PI 401470) and Greece (PI 254976) genotypes also had little inhibitory effects on radish radicle length. Khorasan (Khorasan330) and Egypt (PI 657800) genotypes had the most inhibitory effects on radish radicle length, hypocotyl length, fresh biomass weight and germination percentage. Cyprus (PI 533619) genotype also possessed significant inhibition on radish fresh biomass weight and germination percentage (Table 3).

Investigation of safflower genotypes cultivated under normal irrigation revealed that while Khorasan (Khorasan330) and Egypt (PI 657800) genotypes had the maximum inhibitory effects on growth parameters, Australia
(PI 262424) and Kerman (CTNIR9) genotypes possessed the minimum inhibitory effects (Table 3 ).

\section{Pot experiment}

Irrigation level, type of safflower genotype and plant part used for treatments had significant effects on shoot length and fresh biomass weight at $1 \%$ level and non-significant effects on germination percentage. Interaction effects had no significant impact on measured traits except for the interaction effect of safflower genotype type and plant part type, which had a significant impact on radish fresh biomass weight at $1 \%$ probability level (Table 4 ).

The results of this experiment showed that application of safflower residues in soil caused a reduction in radish shoot length, fresh biomass weight, and germination percentage. The number of radish seedlings grown in the presence of root residues was less than seedlings grown in the presence of shoot residues. Khorasan (Khorasan330) and Egypt (PI657800) genotypes showed the most inhibitory effects on measured traits of radish while Australia (PI 262424) and Kerman (CTNIR9) genotypes had the minimum inhibitory effects. Moreover, the residues of safflower genotypes grown under drought stress had more allelopathic potential (Tables 5, 6). Pot experiment result s were in agreement with in vitro experiment findings.

Table 4. Variance analysis of radish germination traits affected by residues of four safflower genotypes in pot experiment

\begin{tabular}{|c|c|c|c|c|}
\hline Source of variation & Degree of freedom & Shoot length & $\begin{array}{l}\text { Germination } \\
\text { percentage }\end{array}$ & $\begin{array}{c}\text { Fresh biomass } \\
\text { weight }\end{array}$ \\
\hline Genotypes & 3 & $23.29^{* *}$ & $2.35^{* *}$ & $291.66 \mathrm{~ns}$ \\
\hline Irrigation level & 1 & $25.75^{* *}$ & $1.43^{* *}$ & $75.00 \mathrm{~ns}$ \\
\hline Plant part & 1 & $68.30^{* *}$ & $6.43^{* *}$ & 408.33 ns \\
\hline Genotypes $\times$ irrigation level & 3 & $0.10 \mathrm{~ns}$ & $0.06 \mathrm{~ns}$ & $91.66 \mathrm{~ns}$ \\
\hline Genotypes $\times$ plant part & 3 & $0.65 \mathrm{~ns}$ & $0.77^{* *}$ & $69.44 \mathrm{~ns}$ \\
\hline Plant part× irrigation level & 1 & $0.76 \mathrm{~ns}$ & $0.03 \mathrm{~ns}$ & $8.33 \mathrm{~ns}$ \\
\hline Genotypes $\times$ irrigation level $\times$ plant part & 3 & $0.21 \mathrm{~ns}$ & $0.04 \mathrm{~ns}$ & $2.77 \mathrm{~ns}$ \\
\hline Experimental error & 32 & 0.35 & 0.02 & 166.66 \\
\hline $\mathrm{CV} \%$ & & 6.64 & 12.55 & 19.24 \\
\hline
\end{tabular}

**significant at the $1 \%$ probability level; ns - not significant

Table 5. Mean comparison for germination traits of radish affected by allelopathic potential of root residues of four safflower genotypes (pot experiment)

\begin{tabular}{|c|c|c|c|c|c|c|}
\hline \multirow{2}{*}{ Genotype } & \multicolumn{2}{|c|}{$\begin{array}{l}\text { Shoot length } \\
{[\mathrm{cm}]}\end{array}$} & \multicolumn{2}{|c|}{$\begin{array}{c}\text { Fresh biomass weight } \\
{[\mathrm{g}]}\end{array}$} & \multicolumn{2}{|c|}{ Germination percentage } \\
\hline & stress & normal & stress & normal & stress & normal \\
\hline Iran (Khorasan) & 5.7518 & 7.4611 & 0.6741 & 0.8430 & 56.66 & 56.67 \\
\hline Egypt & 5.8611 & 7.6815 & 0.6858 & 0.8693 & 56.65 & 63.33 \\
\hline Iran (Kerman) & 7.7869 & 9.3879 & 0.8818 & 1.2254 & 66.67 & 73.33 \\
\hline Australia & 8.0265 & 9.7631 & 0.9141 & 1.3881 & 66.66 & 73.33 \\
\hline LSD $5 \%$ & \multicolumn{2}{|c|}{1.0678} & \multicolumn{2}{|c|}{0.2075} & \multicolumn{2}{|c|}{21.7745} \\
\hline
\end{tabular}


Table 6. Mean comparison for germination traits of radish affected by allelopathic potential of shoot residues of four safflower genotypes (pot experiment)

\begin{tabular}{|c|c|c|c|c|c|c|}
\hline \multirow{2}{*}{ Genotype } & \multicolumn{2}{|c|}{$\begin{array}{l}\text { Shoot length } \\
{[\mathrm{cm}]}\end{array}$} & \multicolumn{2}{|c|}{$\begin{array}{l}\text { Fresh biomass weight } \\
\qquad[\mathrm{g}]\end{array}$} & \multicolumn{2}{|c|}{ Germination percentage } \\
\hline & stress & normal & stress & normal & stress & normal \\
\hline Iran (Khorasan) & 8.1530 & 9.0542 & 0.9251 & 1.0663 & 66.65 & 70.00 \\
\hline Egypt & 8.0189 & 9.6633 & 0.9196 & 1.3748 & 63.63 & 70.00 \\
\hline Iran (Kerman) & 11.0157 & 12.4357 & 2.0216 & 2.6854 & 66.67 & 73.33 \\
\hline Australia & 10.7890 & 11.6759 & 2.0049 & 2.3413 & 73.33 & 76.67 \\
\hline LSD 5\% & \multicolumn{2}{|c|}{0.9788} & \multicolumn{2}{|c|}{0.3413} & \multicolumn{2}{|c|}{22.8919} \\
\hline
\end{tabular}

\section{Discussion}

The results of this study demonstrated that safflower residues inhibited growth parameters of radish seedlings such as radicle length, hypocotyl length, fresh biomass weight and seed germination percentage. The results are consistent with those of Miri (2011), Farhoudi and Lee (2012), Modhej et al. (2013), and Bonamigo et al. (2013) who reported the inhibitory effect of safflower on growth and germination traits of different plant species. Miri (2011) studied the allelopathic potential of some important crop species on wild barley (H. spontaneum), a major weed of wheat (T. aestivum) in Iran. Most crop species inhibited wild barley germination and root growth. The greatest inhibitory effects were observed in species like sugar beet (Beta vulgaris L. ssp. vulgaris var. altissima), safflower (C. tinctorius), sorghum (Sorghum bicolor L.) and most legume species. Farhoudi and Lee (2012) reported the allelopathic effect of safflower on seed germination and induction of $\alpha$-amylase of wild mustard (S. arvensis). Seed germination, lipid peroxidation malondialdehyde (MDA) concentration, seedling fresh weight and seedling length of wild mustard was reduced when safflower extract concentration was enhanced but mean germination time was reduced. Safflower extracts also inhibited the induction of $\alpha$-amylase in target seeds and the inhibition increased with increasing extract concentrations. Modhej et al. (2013) evaluated the allelopathic effects of four crops including wheat, barley, canola, and safflower on seed germination and embryonic growth of wild mustard by applying different aqueous extract concentrations of the crops. Wild mustard traits were significantly affected by different aqueous extract concentrations of the crops. According to their results, stronger inhibitory allelopathic effects were observed when an aqueous extract of safflower was applied. Bonamigo et al. (2013) reported that the allelopathic effects of safflower aqueous extracts significantly affected seedling emergence and early growth of canola (B. napus). Similar observations have been reported in other plant species. Chung et al. (2001) showed that residues of rice (Oryza sativa L.) genotypes reduced leaf area, dry weight and the number of tillers in barnyard grass (Echinochloa crus-galli L.) in greenhouse and field conditions. Amini et al. (2009) reported that ryegrass (Lolium perenne L.) had an inhibitory effect on wheat root growth. Similarly, Ashrafi et al. (2008) reported that mixing fresh sunflower (Helianthus annuus L.) residues in soil, reduced germination, height, and weight of wild barley more than non-residue (control). According to Niakan et al. (2013), all growth parameters such as length, fresh and dry weight of root and shoot, number and area of sorghum leaves were significantly reduced in response to drought (abiotic stress) and eucalyptus (Eucalyptus globulus Labill.) leaf compost (biotic stress). The reduction resulting from Eucalyptus leaf compost is more severe. Sabagh Nekonam et al. (2014) studied the allelopathic effects of Crocus sativus L., Ricinus communis L., Nicotiana tabacum L., Datura inoxia Mill., Nerium oleander L., and Sorghum vulgare L. on the germination and growth of Amaranthus retroflexus L. (redroot pigweed). All aqueous extracts showed significant inhibitory effects on the germination, seedling length and weight of redroot pigweed plants under laboratory conditions and extracts and the powder of these plants showed significant inhibitory effects on pigweed dry weight, height, leaf area, the number of survivor plants, and the amount of chlorophyll under greenhouse conditions.

The results indicate that safflower shows strong allelopathic activity and safflower residues have growth inhibitory effects. Strong inhibitory allelopathic effects of safflower have been reported in earlier research by Miri (2011) and Modhej et al. (2013).

Different safflower genotypes possess different allelopathic potential. The results of both in vitro and pot experiments revealed that Khorasan (Khorasan330) and Egypt (PI 657800) genotypes had the most inhibitory effects and Australia (PI 262424) and Kerman (CTNIR9) genotypes had the minimum inhibitory effects. Further research could be carried out on these genotypes.

Different parts of safflower plants exhibited variability in allelopathic potential (root > shoot). The difference in allelopathic effects of various plant parts may represent the presence of different allelochemicals or concentrations of allelochemicals in the various plant parts (Miri 2011). Since safflower root residues decreased radish growth parameters more than shoot residues, it may be concluded that allelochemicals are not uniformly distributed in the safflower and that safflower roots possess a higher level of inhibitory chemical substances. It is also possible that there are different allelochemicals in these two parts. Similarly, Miri (2011) compared the inhibitory effects of leaves, stems, and root extracts of different species. There was considerable variation in the distribution 
of allelochemicals in different plant parts. According to his results, safflower stem extract showed lower inhibitory effects on seed germination and root and shoot length of wild barley than leaf and root. Wu et al. (2000b, 2001) also reported that allelochemicals are differently distributed in wheat with roots having a much higher level of allelochemicals than the stem. According to the findings of Nimbal et al. (1996), Czarnota et al. (2003) and Yang et al. (2004), sorgoleone, an allelochemical of sorghum, constituted more than $80 \%$ of root exudate composition but none was found in immature and mature leaves and stems of sorghum. To the best of our knowledge, there is no information about the exact components of allelochemicals in safflower and additional research is required to identify the safflower allelochemicals and their distribution in different safflower parts.

Allelopathic potential of plants is enhanced and induced under environmental stress (Zhu et al. 2010). According to Tang et al. (1995) Tagetes erecta L. produced a higher concentration of phenolics under water stress in comparison with normal water. As reported by Tongma et al. (2001), drought conditions not only directly led to a reduction in plant growth but also increased the allelopathic activity of Mexican sunflower (Tithonia diversifolia L.). Kong et al. (2002) discovered that Ageratum conyzoides L. under water deficit and nutrient stress showed strong allelopathic potential. Emeterio et al. (2004) observed that the inhibitory allelopathic effect of Lolium rigidum Gaud. on the root growth of other plants increased under drought stress. Oueslati et al. (2005) also reported that the auto-toxic effect of Hordeum vulgare L. grown in an arid region was correlated closely with water conditions in the growth season; the most serious drought resulted in stronger auto-toxic effects. Thus, the results of our experiment agree with earlier research which found stronger allelopathic effects under drought stress.

It is essential to study the types of allelochemicals produced and their distribution in different parts of safflower. Further research is absolutely required to test the efficacy of safflower residues or extracts on weed control under field conditions and to identify the exact components of allelochemicals in safflower. The most allelopathic genotype of this study could also be furthered research. It is worth studying the effects of allelochemicals on crop growth under varied growth conditions such as a variety of soil types, water and soil availability, climate conditions, and previous or companion crops. Comprehensive research is required to optimize the appropriate concentrations of allelochemicals, to study their modes of action, to analyze biochemical and genetic properties of safflower and to apply breeding and biotechnology in order to develop potential varieties producing more allelochemicals (Einhellig 1996; Albuquerque et al. 2011; Farooq et al. 2013).

\section{Acknowledgements}

This study was supported by a grant from the research council of the Isfahan University of Technology.

\section{References}

Albuquerque M., Santos R., Lima Melo Filho P., Nogueira R., Camara C., Ramos A. 2011. Allelopathy, an alternative tool to improve cropping systems. A review. Agronomy for Sustainable Development 31 (2): 379-395.

Allen R.G., Pereira L.S., Raes D., Smith M. 1998. Crop evapotranspiration - guidelines for computing crop water requirements. FAO Irrigation and Drainage paper 56, FAO, Rome, Italy, $300 \mathrm{pp}$.

Amini R., An M., Pratley J., Azimi S. 2009. Allelopathic assessment of annual ryegrass (Lolium rigidum): Bioassays. Allelopathy Journal 24 (1): 67-76.

Ashrafi Z.Y., Sadeghi S., Mashhadi H.R., Hassan M.A. 2008. Allelopathic effects of sunflower (Helianthus annuus) on germination and growth of wild barley (Hordeum spontaneum). Journal of Agricultural Technology 4: 219-229.

Bonamigo T., Fortes A.M.T., Pinto T.T., Gomes F.M., Silva J., Buturi C.V. 2013. Allelopathic interference of safflower leaves with oilseed species. Biotemas 26 (2): 1-8.

Chung I.M., Ahn J.K., Yun S.J. 2001. Assessment of allelopathic potential of barnyard grass (Echinochloa crus-galli) on rice (Oryza sativa L.) cultivars. Crop Protection 20 (10): 921-928.

Czarnota M.A., Rimando A.M., Weston L.A. 2003. Evaluation of root exudates of seven sorghum accessions. Journal of Chemical Ecology 29 (9): 2073-2083.

Einhellig F.A. 1995. Interactions involving allelopathy in cropping systems. Agronomy Journal 88 (6): 886-893.

Emeterio L.S., Arroyo A., Canals R.M. 2004. Allelopathic potential of Lolium rigidum Gaud. on the early growth of three associated pasture species. Grass and Forage Science 59 (2): 107-112.

Farhoudi R., Lee D.J. 2012. Evaluation of safflower (Carthamus tinctorius cv. Koseh) extract on germination and induction of $\alpha$-amylase activity of wild mustard (Sinapis arvensis) seeds. Seed Science and Technology 40 (1): 134-138.

Farooq M., Bajwa A.A., Cheema S.A., Cheema Z.A. 2013. Application of allelopathy in crop production. International Journal of Agriculture and Biology 15 (6): 1367-1378.

Fujii Y. 1992. The potential biological control of paddy weeds with allelopathy. Allelopathic effect of some rice varieties. p. 305-320. In: Proceedings of the International Symposium on Biological Control and Integrated Management of Paddy and Aquatic Weeds in Asia. National Agricultural Research Centre, Tsukuba, Japan, 19-25 October 1992.

Fujii Y. 1994. Screening of allelopathic candidates by new specific discrimination, and assessment methods for allelopathy, and the inhibition of L-DOPA as the allelopathic substance from the most promising velvet bean (Mucuna pruriens). Bulletin of National Institute for Agro-Environmental Sciences 10: 115-218. (in Japanese, with English summary)

Fujii Y., Parvez S.S., Parvez M.M., Ohmae Y., Iida O. 2003. Screening of 239 medicinal plant species for allelopathic activity using the sandwich method. Weed Biology and Management 3 (4): 233-241.

Itani T., Nakahata Y., Kato-Noguch H. 2013. Allelopathic activity of some herb plant species. International Journal of Agriculture and Biology 15 (6): 1359-1362.

Kabir A.K.M.S., Karim S.M.R., Begum M., Juraimi A.S. 2010. Allelopathic potential of rice varieties against spinach (Spina- 
cia oleracea). International Journal of Agriculture and Biology 12 (6): 809-815.

Kong C., Hu F., Xu X. 2002. Allelopathic potential and chemical constituents of volatites Ageratum conyzoides under stress. Journal of Chemical Ecology 28 (6): 1173-1182.

Miri H.R. 2011. Allelopathic potential of various plant species on Hordeum spontaneum. Advances in Environmental Biology 5 (11): 3543-3549.

Modhej A., Rafatjoo A., Behdarvandi B. 2013. Allelopathic inhibitory potential of some crop species (wheat, barley, canola, and safflower) and wild mustard (Sinapis arvensis). International Journal of Biosciences 3 (10): 212-220.

Molisch H. 1937. Der Einfluss einer Pflanze auf die Andere Allelopathie [The Effect of Plants on Each Other]. Gustav Fischer, Jena, Germany.

Navarez D.C., Olofsdotter M. 1996. Relay seeding technique for screening allelopathic rice (Oryza sativa L.). p. 1285-1290. In: Proceedings of the 2nd International Weed Control Congress, Copenhagen, Denmark, 25-28 June 1996.

Niakan M., Darvishkhezri M., Iranbakhsh A., Barzegar A. 2013. Changes of sorghum growth in response to drought and allelopathy stresses. Annals of Biological Research 4 (6): $18-22$.

Nimbal Ch.I., Pedersen J.F., Yerkes C.N., Weston L.A., Weller S.C. 1996. Phytotoxicity and distribution of sorgoleone in grain sorghum germplasm. Journal of Agricultural and Food Chemistry 44 (5): 1343-1347.

Nishihara E., Parvez M.M., Araya H., Kawashima S., Fujii Y. 2005. L-3-(3,4-Dihydroxyphenyl)alanine (L-DOPA), an allelochemical exuded from velvetbean (Mucuna pruriens) roots. Plant Growth Regulation 45 (2): 113-120.

Oueslati O., Ben-Hammouda M., Ghorbal M.H., Guezzah M., Kremer R.J. 2005. Barley autotoxicity as influenced by varietal and seasonal variation. Journal of Agronomy and Crop Science 191 (4): 249-254.

Om H., Dhiman S.D., Kumar S., Kumar H. 2002. Allelopathic response of Phalaris minor to crop and weed plants in ricewheat system. Crop Protection 21 (9): 699-705.

Powles S.B., Preston C., Bryan I.B., Jutsum A.R. 1996. Herbicide resistance: impact and management. Advances in Agronomy 58: 57-93.

Pedrol N., Gonzalez L., Reigosa M.J. 2006. Allelopathy: A Physiological Process with Ecological Implications. Springer, Netherlands, $638 \mathrm{pp}$.
Rice E.L. 1984. Allelopathy. 2nd ed. Academic Press, Inc., Orlando, USA, 368 pp.

Sabagh Nekonam M., Razmjoo J., Karimmojeni H., Sharifnabi B., Amini H., Bahrami F. 2014. Assessment of some medicinal plants for their allelopathic potential against redroot pigweed (Amaranthus retroflexus). Journal of Plant Protection Research 54 (1): 90-95.

Tang C.S., Cai W.F., Kohl K., Nishimoto R.K. 1995. Plant stress and allelopathy. ACS Symposium Series 582: 142-147.

Tongma S., Kobayashi K., Usui K. 2001. Allelopathic activity of Mexican sunflower [Tithonia diversifolia (Hemsl.) A. Gray] in soil under natural field conditions and different moisture conditions. Weed Biology and Management 1 (2): 115-119.

Vidal R.A., Bauman T.T. 1997. Fate of allelochemicals in the soil. Ciência Rural 27 (2): 351-357.

Whittaker R.H., Feeny P.P. 1971. Allelochemics: chemical interaction between species. Science 171 (3973): 757-770.

Wu H., Pratley J., Lemerle D., Haig T. 1999. Crop cultivars with allelopathic capability. Weed Research 39 (3): 171-180.

Wu H., Pratley J., Lemerle D., Haig T. 2000a. Evaluation of seedling allelopathy in 453 wheat (Triticum aestivum) accessions against annual ryegrass (Lolium rigidum) by the equal-compartment-agar method. Australian Journal of Agricultural Research 51 (7): 937-944.

Wu H., Pratley J., Lemerle D., Haig T., An M. 2000b. Distribution and exudation of allelochemicals in wheat (Triticum aestivum L.). Journal of Chemical Ecology 26 (9): 2141-2154.

Wu H., Pratley J., Lemerle D., Haig T. 2001. Allelopathy in wheat (Triticum aestivum). Annals of Applied Biology 139 (1): 1-9.

Yang W., Scheffler B.E., Weston L.A. 2004. SOR1, a gene associated with bioherbicide production in sorghum root hairs. Journal of Experimental Botany 55 (406): 2251-2259.

Yousefi Davood M., Karimmojeni H., Khodaee M.M., Sabzalian M.R. 2013. A bioassay assessment of safflower allelopathy using equal compartment agar methods. Journal of Agrobiology 30 (2): 97-106.

Zuo S., Zhi J., Shao H., Zhao G. 2010. Allelopathy regulates wheat genotypes performance at the enhancement stage by soil water and prohydrojasmon (PDJ). African Journal of Biotechnology 9 (33): 5430-5440. 